\title{
Factorial Analysis of Vertical Ground Reaction Force and Required Coefficient of Friction for Safety of Stair Ascent and Descent
}

\section{Xuejun Qian ${ }^{1,2}$, Guangming Chen ${ }^{1 *}$, Bheem Kattel', Seong Lee ${ }^{1,2}$ and Yulai Yang ${ }^{1,2}$}

${ }^{1}$ Industrial and Systems Engineering Department, Morgan State University, USA

${ }^{2}$ Center for Advanced Energy Systems and Environmental Technologies, School of Engineering, Morgan State University, USA

\begin{abstract}
Slipping and falling on ascent and descent stairs often lead to high risk of injuries and fatalities. In this paper, factorial analysis was used to study various factors influential to the biomechanics, such as ground reaction force (GRF) and required coefficient of friction (RCOF). The purpose of this study is to investigate the effect of the factors, such as stairs, climbing style, climbing mode and participants on vertical GRF and RCOFs. Ten healthy younger adults were asked to perform two replicates of each trial under twelve different conditions (two climbing modes: Ascent and decent; three different stair heights: $0.165 \mathrm{~m}, 0.173 \mathrm{~m}$ and $0.178 \mathrm{~m}$; two climbing styles: Walking and running). Force platform was used to measure both vertical and horizontal GRF. In addition, participant's body weight, stature and average time spent on each condition were recorded. Analysis of variance (ANOVA) results indicated that the effect of climbing mode, climbing style and participants on vertical GRF were significant. Descending requires more vertical GRF than ascending while running requires more vertical GRF than walking. The possible reason of increasing vertical GRF may be explained by increasing gait speed as well as whole body momentum. Compared with vertical GRF, only climbing mode and style show significant effects on RCOFs. RCOF during foot landing $\left(\mathrm{RCOF}_{\mathrm{FL}}\right)$ is larger than RCOF during pushoff $\left(\mathrm{RCOF}_{\mathrm{PO}}\right)$ for stair descent and ascent while both $\mathrm{RCOF}_{\mathrm{FL}}$ and $\mathrm{RCOF}_{\mathrm{PO}}$ of running are higher than walking. These results indicate that running is not recommended when descending, as it requires highest vertical GRF as well as RCOFs during stair climbing. In the future study, more female participants and force platforms can be used to study the effect of gender and position of steps on GRF and RCOFs during complete cycle of stair descending and ascending. In addition, different stair heights with same stair total length may be selected to identify effect of stair height on biomechanics.
\end{abstract}

\section{Keywords}

Ergonomics, Stair safety, Factorial design, Ground reaction force, Required coefficient of friction

*Corresponding author: Guangming Chen, Industrial and Systems Engineering Department, Morgan State University, 1700 East Cold Spring Lane, Baltimore, MD 21251, USA, Tel: +1-443-885-4243

Accepted: December 12, 2018; Published: December 14, 2018

Copyright: (C) 2018 Qian X, et al. This is an open-access article distributed under the terms of the Creative Commons Attribution License, which permits unrestricted use, distribution, and reproduction in any medium, provided the original author and source are credited.

Qian et al. Int J Ind Operations Res 2018, 1:002 


\section{Introduction}

Stair ascent and descent are common daily activities of people. In both public and residential buildings, such as schools, hospitals, transit stations, shopping centers and apartments, there are signs in front of elevators encouraging people to use stairs because walking up and down through stairs can save energy and it is also good for health [1]. However, stair ascent and descent present greater biomechanical challenge than walking on level ground because body center-of-mass is raised during ascent and lowered during descent with single leg support while maintaining forward progression and proper foot placement [2]. Many studies have found that physical demand and risk for stair climbing is higher than level-ground walking [3]. Falling and slipping during stair climbing may lead to high risk of death or severe injuries with longterm disability [4]. Falling is one of the leading causes of injury at both home and work place. Slipping is the second leading cause of falls, accounting for $25 \%$ of all fall incidents [5]. It is estimated the annual direct cost of occupational injuries due to slips, trips, and falls in USA exceeds 6 billion dollars [6]. Several studies have investigated the biomechanics during stair climbing, including joint kinematics, joint kinetics, GRF, and electromyography (EMG). To prevent fall accidents and slip propensity, GRFs and RCOFs are widely adopted as a standard measure for the biomechanical analysis of stair climbing $[1,5,7]$.

GRF is one of the most common responses to evaluate the human performance during gait, jogging, jumping, running, and stair climbing [8]. GRF represents a force that acts from ground on any contacted structures during the entire action and can be measured to track the reasons associated with fall at stair climbing. GRF includes vertical GRF (or normal force), horizontal GRF (or parallel force) and medio-lateral GRF. The force platform was designed to measure GRFs and frequently used to diagnose and treat various disabilities affecting walking gait, running gait and postural stability in humans as well as in animals [9]. Thus, the analysis of GRFs by force platform is critical to quantify the magnitude of forces sustained by body structures during the movement [8]. Several studies used GRF as one of the evaluation measures. Effect of several factors, namely age, illumination level, task difficulty, movement speed, floor surfaces, and stair heights on GRFs during common human activities (e.g., stair climbing, level walking, and treadmill running) have been also analyzed and investigated. Christina and Cavanagh studied the effect of age and illumination conditions on GRF during stair descent. Two force plates were located on independent concrete at stair 2 and stair 4 to measure the GRF. The results indicated that elderly participants had slightly higher vertical GRF and lower horizontal GRF than younger participants during stair descent [7]. However, only minor effect of illumination level was identified. Bertucco and Cesari studied effects of different ages on GRF during stair climbing [10]. A force platform was placed at edge of stairs and recorded in 3D GRF at sampling rate of $100 \mathrm{~Hz}$. It was found that younger adults presented a significantly higher vertical GRF than older adults. Kluitenberg, et al. analyzed the effect of gait speeds on vertical GRF during over ground and treadmill running at slow, preferred and fast self-selected running speeds [11]. GRFs were collected at sample rate of $1000 \mathrm{~Hz}$ with a force platform which was mounted in the middle of $17.5 \mathrm{~m}$ long runway. Results showed that vertical GRF was elevated by increasing running speeds during both over ground and treadmill running. Silva, et al. analyzed the relationship between knee angular velocity and vertical GRF of young and elderly persons during stair descent. A force plate measuring was fixed in the center of the fourth step of the stairs to measure GRF. Results indicated that the elderly persons had a lower knee angular velocity and vertical GRF than the young persons during stair decent [12]. Recently, Li, et al. further measured and compared vertical GRF under four different floor coverings of force platform and two stepping conditions [1]. A force platform was rigidly mounted on a concrete ground as the first stair to collect the GRF of the subject. It was determined that the effect of floor covering on vertical GRF was not significantly different from stepping condition. From the previous studies, it was found that force platform was placed in the different stairs/steps to measure GRF. In addition, previous studies found that effect of ages, participants, velocity, stepping condition on the GRF were significant than the illumination levels and floor coverings. However, the effect of stairs and its interaction with other factors on GRF were barely studied.

Coefficient of friction (COF) is the ratio between horizontal GRF $\left(F_{h}\right)$ and vertical GRF $\left(F_{z}\right)$ exerted between the shoe and floor $[1,7,13]$. The peak 
value of COF during a gait is defined as RCOF [1]. There are two peak values of RCOF, which typically occur shortly after foot landing (or foot strike) and just prior to push-off $[1,7,13]$. High RCOF has been hypothesized to be a major factor in occupational stair accidents. To prevent accidental falls and slips, the RCOFs must be lower than COF at the shoefloor interface (known as available COF). Therefore, RCOFs can be useful tools in assessing slip potential and preventing slipping [5]. While many studies have reported the effects of age, walking speeds, obstacle height, turning strategies, stride length, and floor coverings, only few studies have been reported for stair height. Christina and Cavanagh found that the older participants have lower RCOF than younger adults during stair descent [7]. RCOFs were calculated by diving the magnitude of the vector sum of the shear forces (horizontal GRF) by the vertical force (vertical GRF) at each sample in time. The peak RCOF just after foot-strike and just before push-off were obtained using a peak detection algorithm. In addition, RCOF used as a measure to examine the effects of age, illuminance and stair location during the stair descent. The reported maximum RCOF values were between 0.5 and 0.7 for foot strike and from 0.36 to 0.42 for toe push-off. Chang, et al. investigated the effects of walking speeds (fast, normal) and footwear types (sneaker, leather loafer) on RCOF of left and right foot [14]. As expected, RCOF at the fast speed was higher than that at the normal speed and RCOF while sneaker appeared to be slightly higher than for leather loafer. Fino, et al. studied the relationship between RCOF and gait speed, obstacle height, and turning strategy as participants walked around corner pylons. Results showed that increasing gait speed elevated the peak RCOF at push-off whereas obstacle height had no effect on RCOFs [5]. Chen, et al. further investigated the effects of stride length on RCOF in both ground level walking and stair climbing. Results indicated that RCOF of stair climbing was higher than ground-level walking, and full stride (double half stride) was higher than half stride (averaged stride length) [13]. Li, et al. found that floor coverings had a significant effect on both RCOFs while the mean RCOF ranged from 0.086 to 0.245 for foot landing and from 0.051 to 0.246 for foot push-off, respectively [1].

Gait speeds showed significant effects on both GRF and RCOF during stair ascent and descent. Fruin (1971) measured free flow stair walk speeds of 700 males and females of various ages, both descending and ascending stairs with two different slopes: $31.9^{\circ}$ and $26.5^{\circ}$ [15]. Result indicated that males have average speed of $0.88 \mathrm{~m} / \mathrm{s}$ and 0.63 $\mathrm{m} / \mathrm{s}$ while females have average speeds of $0.67 \mathrm{~m} / \mathrm{s}$ and $0.59 \mathrm{~m} / \mathrm{s}$, for stair descending and ascending respectively. Recently, Choi, et al. found that the average decent speed for male and female population was $0.83 \mathrm{~m} / \mathrm{s}$ and $0.74 \mathrm{~m} / \mathrm{s}$, while the average ascent speed was $0.66 \mathrm{~m} / \mathrm{s}$ and 0.48 $\mathrm{m} / \mathrm{s}$ in a 50-storey residential building [16]. Both experimental results indicated that descending speed was higher than ascending speed and males moved faster than females in most cases. These findings further confirmed that climbing modes, ascent and descent, had an influence on gait speed which may subsequently affect biomechanics (e.g. GRF, RCOF). In addition, two climbing styles, walking and running were also distinguished by gait speeds in previous studies. Selection of different stair heights outside the laboratory can analyze the effect of stair height and overcome the difficulty to simulate natural running at a constant speed in a laboratory instrumented staircase. Qian, et al. conducted a preliminary study to explore the effect of factors, such as stair heights, climbing modes, and climbing styles on vertical GRF by using public stairways [17]. However, there were few limitations of previous studies, such as no consideration of horizontal GRF as well as RCOF during foot strike and push-off to scientifically understand the effect of factors on biomechanical data during stair ascent and descent.

The objective of this study was to further investigate the effect of factors, such as stair heights, climbing modes and climbing styles on the GRFs as well as two peak RCOF values during stair ascent and descent. In addition, relationship between the body weight and vertical GRF as well as momentum and vertical GRF were further analyzed to explain the possible reasons of significant factor effect on GRF and RCOF.

\section{Materials and Methods}

\section{Subjects and protocol used}

In this study, ten healthy volunteers (nine males and one female) from the Morgan State University student population were recruited. All subjects had no history of any musculoskeletal injuries in the lower limbs or neurological impairments that might affect normal gait. Participants were instructed 

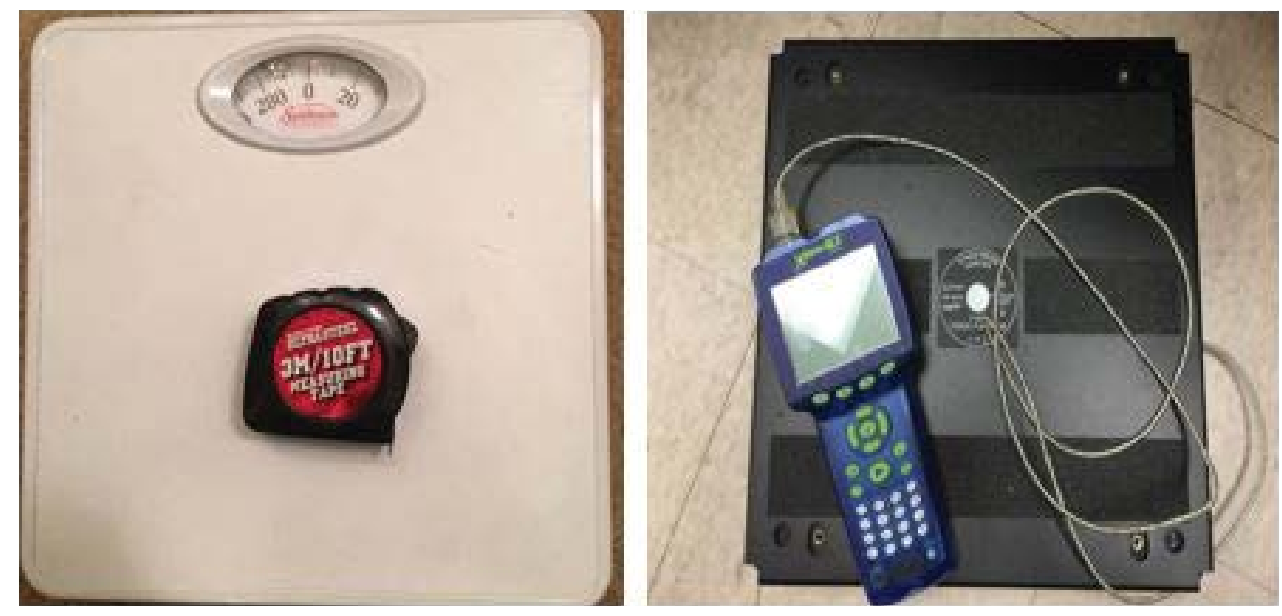

Figure 1: Major instrumentations for anthropometry and GRF data collection.

Table 1: Participants' anthropometry.

\begin{tabular}{|l|l|l|l|l|l|l|l|l|l|l|}
\hline Participant No. & $\mathbf{1}$ & $\mathbf{2}$ & $\mathbf{3}$ & $\mathbf{4}$ & $\mathbf{5}$ & $\mathbf{6}$ & $\mathbf{7}$ & $\mathbf{8}$ & $\mathbf{9}$ & $\mathbf{1 0}$ \\
\hline Gender & Male & Female & Male & Male & Male & Male & Male & Male & Male & Male \\
\hline Stature $(\mathrm{m})$ & 1.69 & 1.64 & 1.63 & 1.80 & 1.63 & 1.80 & 1.85 & 1.78 & 1.66 & 1.68 \\
\hline Mass $(\mathrm{kg})$ & 59.0 & 51.3 & 69.9 & 74.8 & 58.5 & 98.0 & 79.4 & 76.2 & 55.8 & 52.6 \\
\hline
\end{tabular}

Table 2: Summary of stair measurements.

\begin{tabular}{|l|l|l|l|}
\hline Stair No. & $\begin{array}{l}\text { Step Height } \\
(\mathbf{m})\end{array}$ & $\begin{array}{l}\text { Step Width } \\
(\mathbf{m})\end{array}$ & $\begin{array}{l}\text { Stair Total } \\
\text { Length }(\mathbf{m})\end{array}$ \\
\hline Stair 1 & 0.173 & 0.305 & 3.556 \\
\hline Stair 2 & 0.178 & 0.305 & 5.334 \\
\hline Stair 3 & 0.165 & 0.279 & 2.794 \\
\hline
\end{tabular}

about purposes and procedures of study. All participants were given the informed consent prior to participating in experiment. As shown in Figure 1, weight scale, tape measure and force platform along with data recorder were used to collect the experimental results. Anthropometric data were collected as follows: First, body mass of the subjects using a weight scale, and second, height of the subjects using a tape measure. Table 1 provides the summary of anthropometric data, including gender, stature, and mass related to the participants of the study. Two-axis force platform (PASCO-2142, CA, USA; Range: $-1,100 \mathrm{~N}$ to $+4,400$ $\mathrm{N}$, Resolution: $0.1 \mathrm{~N}$ ) was used to record in vertical and horizontal GRFs at a sampling rate of $10 \mathrm{~Hz}$. The dimension of force platform is $355.6 \mathrm{~mm} \times 355.6$ $\mathrm{mm}$ (14 inch $\times 14$ inch). There are total of 5 force beams in the force platform: Four corner beams to measure total vertical GRF and the fifth beam to measure horizontal GRF simultaneously. Data recorder (Xpoler GLX, PASCO-2002, CA, USA) was connected to the force platform to collect and store results in real-time. In addition, PASCO Capstone software was used to export and convert glx data into txt format. Then, two peak values of RCOFs were calculated by dividing instant horizontal GRF by vertical GRF (Figure 1 and Table 1).

As shown in Figure 2, three different stair heights of stairways were selected within the School of Engineering Building, Morgan State University. All stairways have handrails on both sides. However, the participants were requested to use them only if needed. Table 2 shows detailed measurements of stair height (or step height), width and length for three different stairs used in the experiment. Participants were asked to perform test at stair height of $0.173 \mathrm{~m} 0.178 \mathrm{~m}$ and $0.165 \mathrm{~m}$, respectively. Two different climbing modes (stair ascent and descent) and two climbing styles (walking and running) were also preset. For a total of twelve different conditions, all ten subjects performed two trials in each condition. Hence, there were a total of 240 data points collected for analysis of GRF. In the meantime, there were a total of 120 data points available for the analysis of RCOFs because both horizontal and vertical GRF data were only collected in the case of participants $5,6,7,8,9$ and 10. Mean ROCFs of five participants during foot landing and push-off were used to conduct the mixed factorial design analysis and identify the effectiveness of the factors, namely stair heights, climbing mode and climbing styles on RCOF changes (Figure 2 and Table 2). 

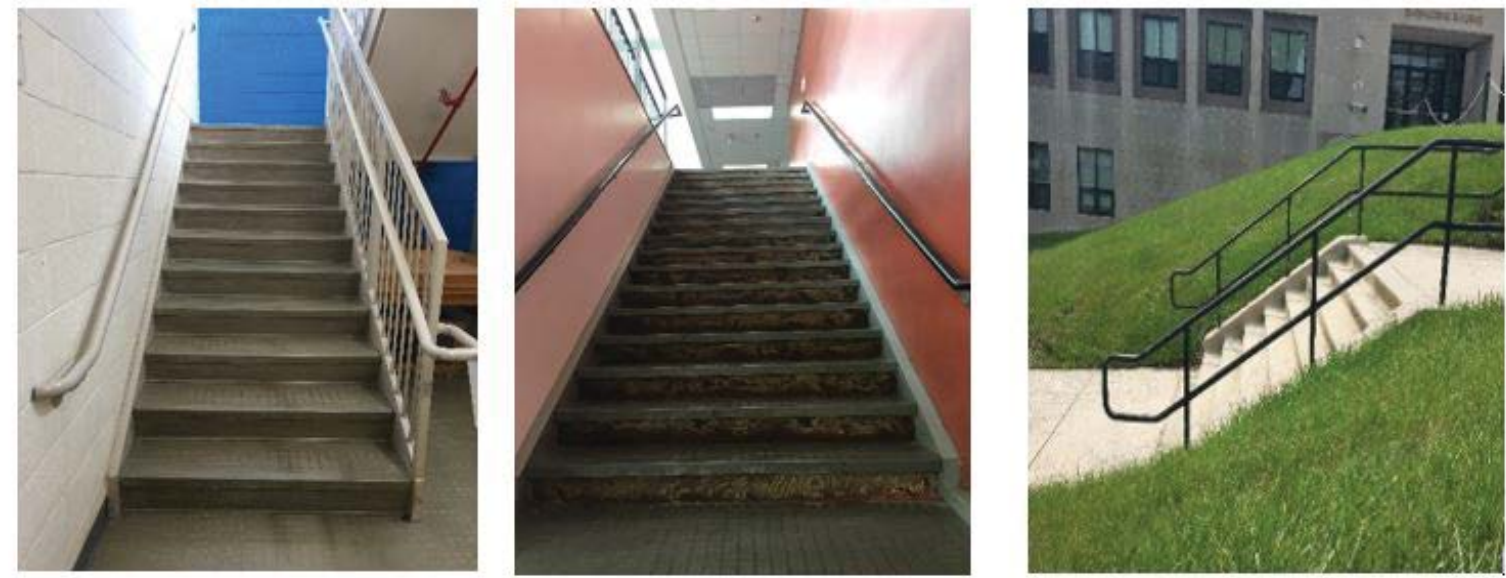

Figure 2: Schematic diagram of three stairs.
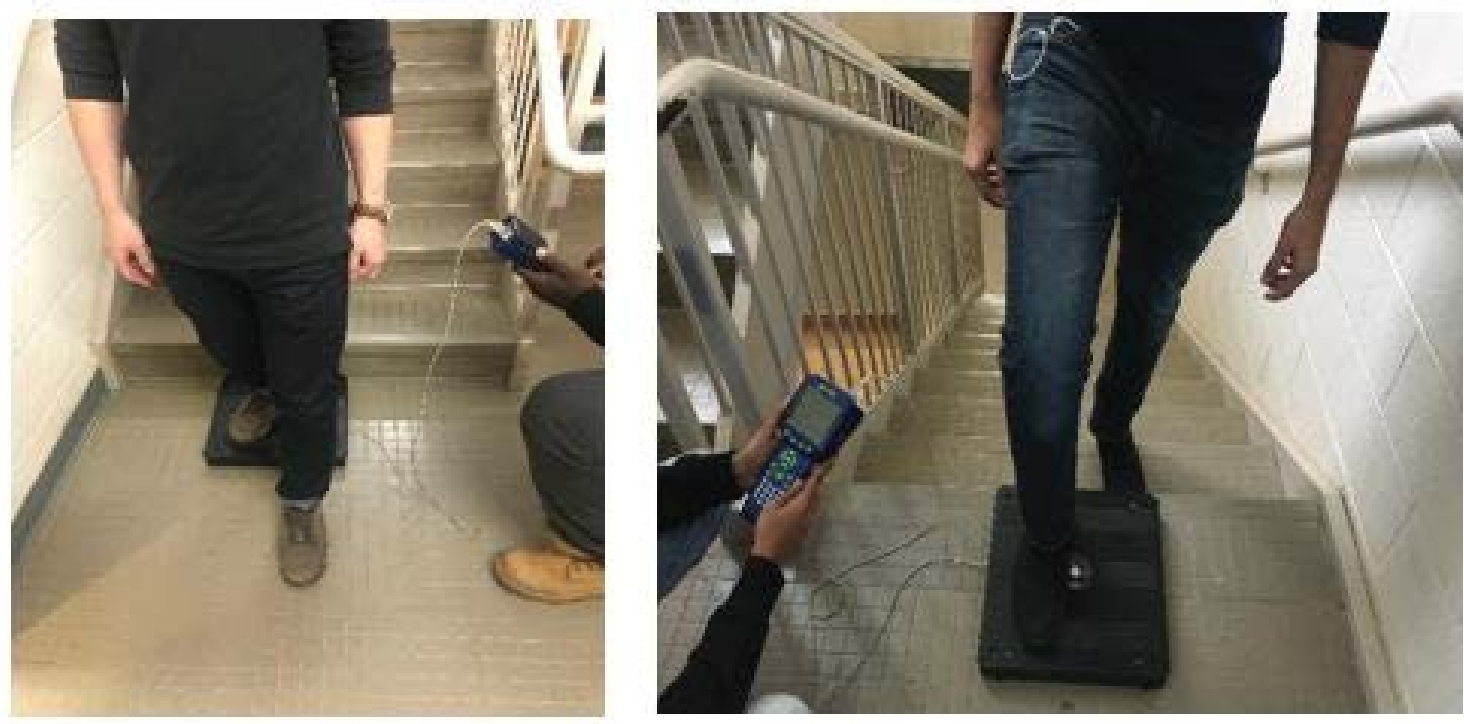

Figure 3: Experimental setup and data collection during stair ascent and descent.

\section{Experimental procedure}

As shown in Figure 3, force platform was setup stably in the center of the first step (for descent) and last step (for ascent) of the stairs to collect the both vertical and horizontal GRF of the subject. Instead of wearing unique laboratory shoes, each subject was asked to wear their personal shoes which mimicked the real-world situations that everybody may wear different types of shoes during stair descent and ascent. The subject started at the level ground at approximately $300 \mathrm{~mm}$ (one step) in front of first stair. Subject stepped directly onto the first step of the stairs and continued climbing up until stepping over last steps. Afterward, the subject started approximately $300 \mathrm{~mm}$ (one step) to nosing of the top stair and stepped down to descend from the top of the stairways and returned to the origin on the level ground. Each subject was asked to perform both walking and running activities at their preferred and comfortable speed. For safety of the participants and successful data collection, the participants performed several runs for accommodation. Then, the participants were given several minutes to warm-up and get rest before performing the actual trial. After each test of climbing up and down at one stair height, participants were given additional few minutes to rest to avoid the effect of fatigue. During the test, participants were also allowed to take a rest anytime if they felt tired. The participants started stair ambulation with right leg or left leg for different stairs but required to touch the force platform by their right leg for all trials. Average time for each condition was measured and recorded by a stopwatch. In order to control participants' final 
touch is right leg for each experiment, participants were asked to start with either start stair climbing with left-side or right-side leg for individual stairs. During the practice and warm-up, participants were identified which starting leg and start with same leg during formal experiment. In addition, participants were suggested to step one stair each time for the whole stair climbing process. Participants performed the planned test in the sequence of stair 1 , stair 2 and stair 3 . Between each test, enough rest time were given to mitigate effect of fatigue and difficulty to reduce the speed of walking and running (Figure 3).

\section{Statistical analysis}

Due to facts that factors with different levels, mixed level factorial design and analysis of variance (ANOVA) [17-20] were conducted to analyze the data and investigate the effect of factors, including stairs, climbing modes (ascent, descent) and climbing styles (walking, running), and participants on both GRFs and RCOFs. All statistical analyses were performed by using the software package Minitab version 17. Statistical significance was set at 5\% and Microsoft Excel 2016 were adopted for data processing.

\section{Results and Discussion}

\section{Factors effect on Ground Reaction Force (GRF)}

As shown in Table 3, the peak values of vertical GRF for the individual participants were under twelve different experimental conditions (three stair heights: Stair 1, stair 2, stair 3, two climbing modes: Ascent/descent, two climbing styles: Walk- ing/running). Mean vertical GRF, which represented the average of two trials' peak values of vertical GRF for all participants, were calculated and used for further data analysis. The minimum vertical GRF of $397.7 \mathrm{~N}$ and maximum vertical GRF of $1498 \mathrm{~N}$ were generated for participant 1 and participant 6 , respectively. There was big difference (more than $1000 \mathrm{~N}$ ) between minimum and maximum vertical GRF because of the participants under conditions (e.g. stairs, climbing mode, climbing style). At individual stair height, it was found that running required more vertical GRF than walking, while stair descent required more vertical GRF than stair ascent (Table 3).

Table 4 summarizes the average time of two trials under twelve different conditions. Then, average time and stair total length was used to calculate average descending and ascending speed during walking and running conditions. Results indicated that average descending speed $(0.64$ $\mathrm{m} / \mathrm{s}$ ) were larger than ascending speed $(0.58$ $\mathrm{m} / \mathrm{s}$ ) under walking condition. Same trend was found that the average descending speed $(0.97$ $\mathrm{m} / \mathrm{s})$ was also larger than ascending $(0.85 \mathrm{~m} / \mathrm{s})$ under running condition. Thus, it proved that stair descending speed is larger than ascending speed. Previous studies also indicated that descending speed is larger than ascending speed. The average stair descending speed was in the range of 0.67 $\mathrm{m} / \mathrm{s}-0.88 \mathrm{~m} / \mathrm{s}$ and stair ascending speed was in the range of $0.48 \mathrm{~m} / \mathrm{s}-0.66 \mathrm{~m} / \mathrm{s}$ respectively [16]. In addition, it showed both walking and running during stair climbing is smaller than normal walking $(1.0-3.0 \mathrm{~m} / \mathrm{s})$ and running $(1.5-6.0 \mathrm{~m} / \mathrm{s})$ on level

Table 3: Average peak values of vertical GRF collection from participants.

\begin{tabular}{|c|c|c|c|c|c|c|c|c|c|c|c|c|c|}
\hline \multirow[b]{2}{*}{ Stair (\#) } & \multirow[b]{2}{*}{ M. } & \multirow[b]{2}{*}{ S. } & \multicolumn{11}{|c|}{ Vertical GRF (N) } \\
\hline & & & P1 & P2 & P3 & P4 & P5 & P6 & P7 & P8 & P9 & P10 & Mean \\
\hline 1 & A. & W. & 623.4 & 539.5 & 671.9 & 738.2 & 570.1 & 1053.4 & 794.3 & 711.9 & 559.1 & 514.3 & 677.6 \\
\hline 1 & D. & W. & 795.8 & 591.0 & 711.0 & 801.7 & 726.1 & 1417.8 & 928.7 & 1183.5 & 687.9 & 688.2 & 853.1 \\
\hline 1 & A. & $\mathrm{R}$. & 652.3 & 591.1 & 880.3 & 828.6 & 690.7 & 1171.6 & 983.0 & 948.0 & 795.4 & 692.9 & 823.4 \\
\hline 1 & D. & $\mathrm{R}$. & 938.2 & 735.4 & 954.9 & 954.6 & 821.0 & 1402.0 & 1536.6 & 1140.7 & 826.8 & 804.9 & 1011.5 \\
\hline 2 & A. & W. & 454.1 & 447.2 & 671.3 & 703.6 & 591.4 & 1081.7 & 783.8 & 707.5 & 584.5 & 521.2 & 654.6 \\
\hline 2 & D. & W. & 702.7 & 656.2 & 788.3 & 758.9 & 763.0 & 1337.2 & 922.9 & 1048.2 & 685.5 & 650.8 & 831.4 \\
\hline 2 & A. & R. & 461.2 & 694.7 & 843.0 & 830.5 & 752.1 & 1157.3 & 851.2 & 1146.6 & 696.3 & 590.4 & 802.3 \\
\hline 2 & D. & R. & 1001.3 & 801.8 & 940.6 & 1051.3 & 825.8 & 1498.0 & 1241.6 & 974.7 & 871.6 & 690.8 & 989.7 \\
\hline 3 & A. & W. & 550.1 & 397.7 & 601.0 & 752.3 & 584.7 & 1080.5 & 810.4 & 712.4 & 595.6 & 543.5 & 662.8 \\
\hline 3 & D. & W. & 427.7 & 488.2 & 704.9 & 857.5 & 687.0 & 1324.5 & 1173.2 & 1278.7 & 825.8 & 785.4 & 855.3 \\
\hline 3 & A. & R. & 784.2 & 691.1 & 818.4 & 892.0 & 699.7 & 1321.8 & 871.0 & 988.0 & 727.8 & 660.5 & 845.4 \\
\hline 3 & D. & R. & 1034.1 & 902.6 & 962.9 & 1012.8 & 795.3 & 1471.2 & 1389.0 & 1319.0 & 840.1 & 832.0 & 1055.9 \\
\hline
\end{tabular}

${ }^{*}$ M. = Climbing Mode; S. = Climbing Style; A. = Ascent; D. = Descent; W. = Walking; R. = Running; P= Participant. 
Table 4: Average time from participants for different activities.

\begin{tabular}{|l|l|l|l|l|l|l|l|l|l|l|l|l|l|}
\hline & \multicolumn{10}{|c|}{} & \multicolumn{10}{|c|}{ Average Time for Different Activities (S) } \\
\hline Stair (\#) & M. & S. & P1 & P2 & P3 & P4 & P5 & P6 & P7 & P8 & P9 & P10 & Mean \\
\hline 1 & A. & W. & 5.9 & 6.1 & 6.6 & 6.7 & 5.6 & 7.4 & 6.2 & 8.4 & 7.0 & 6.3 & 6.6 \\
\hline 1 & D. & W. & 4.8 & 5.4 & 6.7 & 5.3 & 5.4 & 6.3 & 5.8 & 7.8 & 6.2 & 7.4 & 6.1 \\
\hline 1 & A. & R. & 4.3 & 4.3 & 5.6 & 3.4 & 5.2 & 4.2 & 4.8 & 6.4 & 3.9 & 4.0 & 4.6 \\
\hline 1 & D. & R. & 3.6 & 4.1 & 3.3 & 2.4 & 4.5 & 4.7 & 3.7 & 4.5 & 3.6 & 5.3 & 4.0 \\
\hline 2 & A. & W. & 7.8 & 8.3 & 9.3 & 7.7 & 7.8 & 10.1 & 9.9 & 7.8 & 9.6 & 8.7 & 8.7 \\
\hline 2 & D. & W. & 6.7 & 8.1 & 7.2 & 6.3 & 7.0 & 9.2 & 9.0 & 7.4 & 10.0 & 9.8 & 8.1 \\
\hline 2 & A. & R. & 5.1 & 5.5 & 6.1 & 5.0 & 5.9 & 7.1 & 6.0 & 5.3 & 5.9 & 5.3 & 5.7 \\
\hline 2 & D. & R. & 5.1 & 5.4 & 4.4 & 4.4 & 5.3 & 6.6 & 5.0 & 3.8 & 5.4 & 5.3 & 5.1 \\
\hline 3 & A. & W. & 4.4 & 5.2 & 4.3 & 4.4 & 4.2 & 5.1 & 4.7 & 4.1 & 4.7 & 5.7 & 4.7 \\
\hline 3 & D. & W. & 3.6 & 4.1 & 3.4 & 3.3 & 4.0 & 4.7 & 3.7 & 4.0 & 4.5 & 5.3 & 4.1 \\
\hline 3 & A. & R. & 3.0 & 2.9 & 3.9 & 3.4 & 4.0 & 4.0 & 2.3 & 3.0 & 2.4 & 3.8 & 3.3 \\
\hline 3 & D. & R. & 2.7 & 2.9 & 2.5 & 2.8 & 3.5 & 3.9 & 2.3 & 2.5 & 2.8 & 3.4 & 2.9 \\
\hline
\end{tabular}

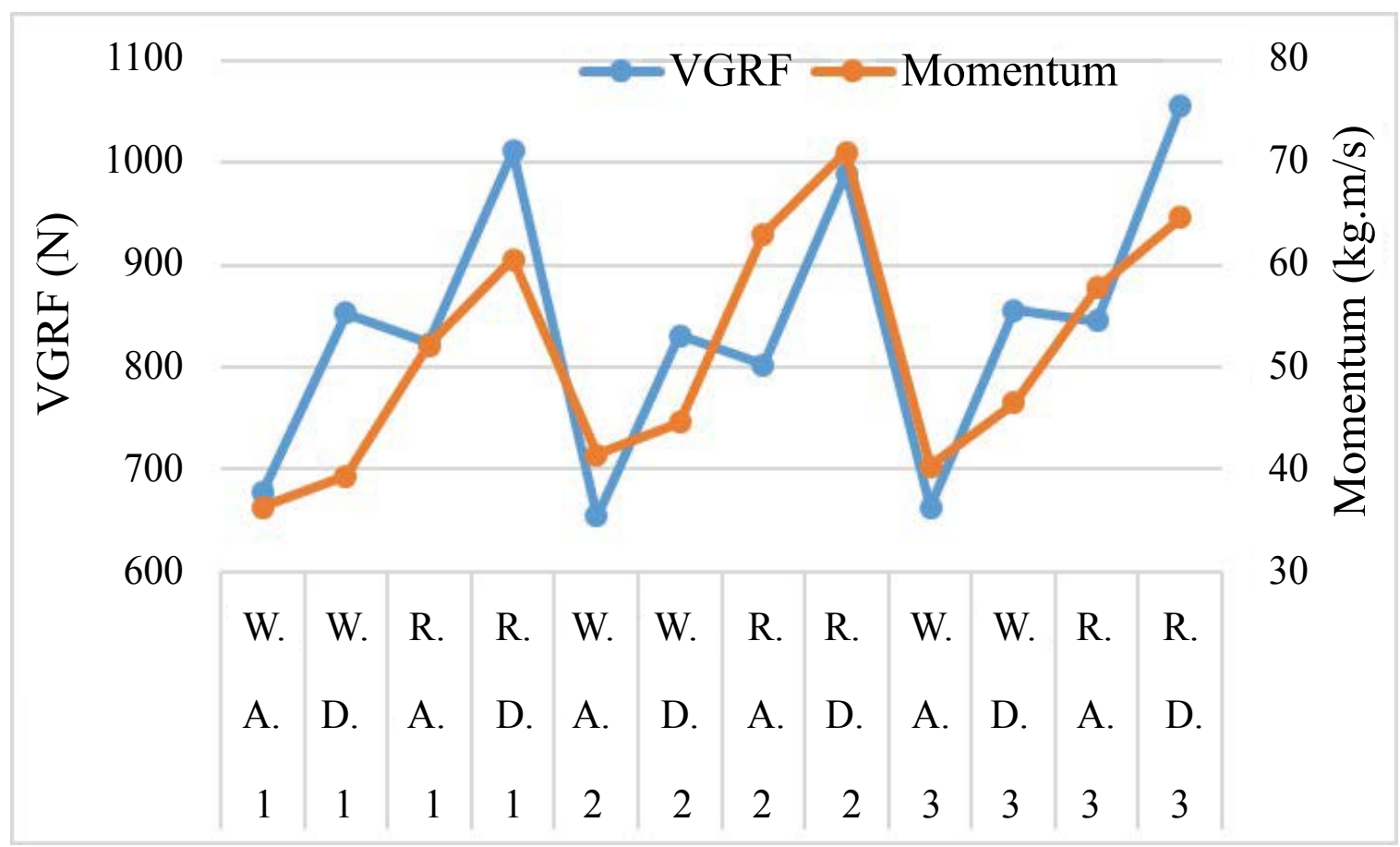

Figure 4: Correlation between momentum and mean vertical GRF.

ground $[5,21,22]$. Running is a preferred mode of locomotion at higher speeds ( $>2.0 \mathrm{~m} / \mathrm{s})$, but these results indicated that participants showed safety awareness during stair descent and ascent than level ground to avoid slip and fall accidents [23]. Participants may also reduce the speed during stair ascent and decent because of the difficulty during stair climbing activities, but the chance of difficulty is smaller than safety awareness because the participants practiced for several times and they were allowed to take rest if participants feel tired for mitigating the difficulty in this study (Table 4).

Stair climbing velocity and average mass of ten participants were used to calculate whole-body momentum and correlation between momentums and associated mean vertical GRF. As shown in Figure 4, increasing momentum proportionally increase mean vertical GRF in all three different stair heights. It confirms that the high-speed during stair climbing may generate high momentum as well as high vertical GRF at different stair heights. The similar results were found in previous research studies. Nilsson and Thorstensson found that peak amplitude of the vertical GRF in walking (1.0-3.0 $\mathrm{m} / \mathrm{s})$ and running $(1.5-6.0 \mathrm{~m} / \mathrm{s})$ increased with speed from approximately 1.0-1.5 body weight 
(BW) and 2.0 - 2.9 BW, respectively [21]. Grabowski and Kram also discovered that GRFs increase when runners increase velocity, which may increase the risk of an overuse injury, and more metabolic power is required to produce greater rates of muscular force generation [24]. Thus, high speed may increase the risk of fall or slip accidents of the participants during the stair ascent and descent (Figure 4).
Furthermore, the relationship between the body weight (BW) and peak values of vertical GRF generated at various stair heights is shown in Figure 5. At individual stair height, there was an increasing trend of vertical GRF by BW. The average peak values of vertical GRF from 3 different stairs (blue line) were consistent with previous results (higher BW normally applied a higher vertical GRF during stair climbing). It was in accordance with results

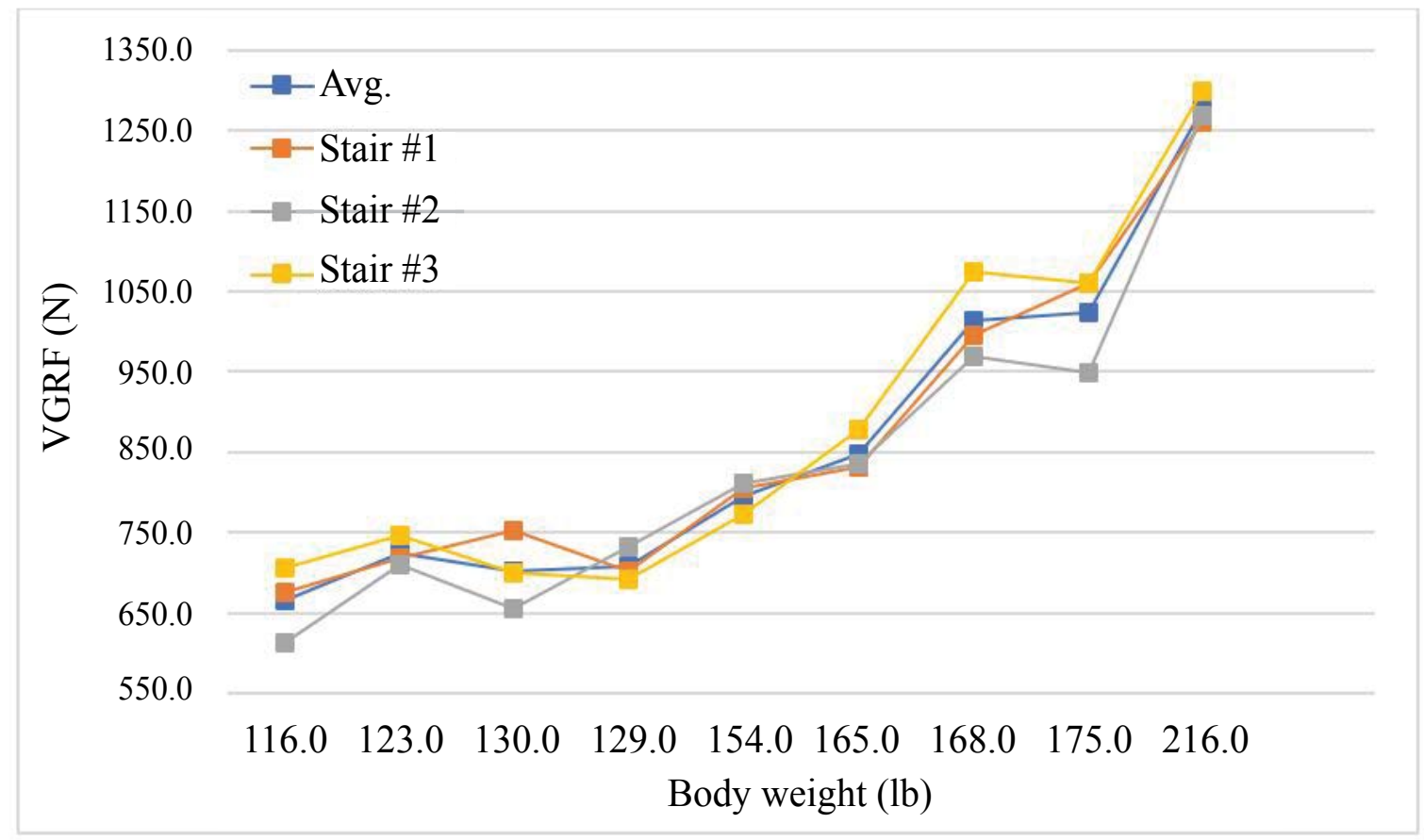

Figure 5: Relationship between vertical RGF vs. BW.

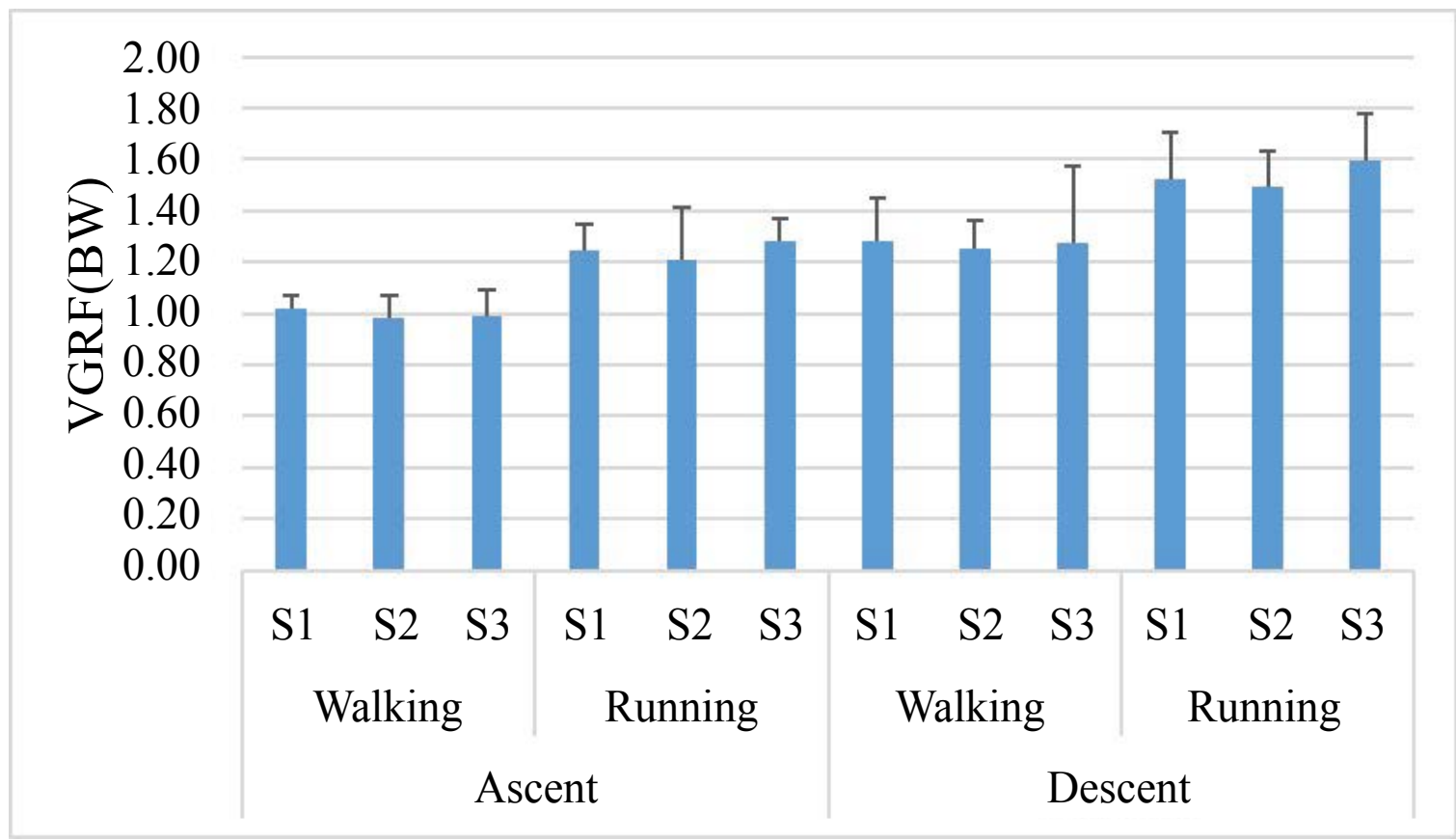

Figure 6: Mean and standard deviation of vertical GRF during foot landing. 
that added weights by carrying packs increased both first and second peak GRF during walk-to-run gait transition [23] (Figure 5).

The vertical GRF (in N) were normalized with respect to BW. Figure 6 and Table 5 shows the mean and standard deviation (SD) of vertical GRF during the foot landing $\left(\mathrm{F}_{\mathrm{VGRF}}\right)$ for all subjects under twelve experimental conditions. For stair ascent, the mean $\mathrm{F}_{\mathrm{VGRF}}$ from $0.98 \mathrm{BW}$ to $1.28 \mathrm{BW}$. For stair descent, the mean $\mathrm{F}_{\mathrm{VGRF}}$ from 1.25 BW to $1.60 \mathrm{BW}$. Results indicated mean $\mathrm{F}_{\mathrm{VGRF}}$ of stair descent was slightly higher than stair ascent and more energy was required to perform stair descent. In addition, mean $F_{\text {VGRF }}$ for running condition (1.25 BW) was slightly higher than that of walking condition (1.00 BW) under stair ascent. A similar result was found average $F_{V G R F}$ for running condition (1.54 BW) was slightly higher than that of walking condition (1.27 BW) under stair descent. It confirmed that running

Table 5: Summary of vertical GRF during foot landing.

\begin{tabular}{|c|c|c|c|c|}
\hline $\begin{array}{l}\text { Climbing } \\
\text { Mode }\end{array}$ & $\begin{array}{l}\text { Climbing } \\
\text { Style }\end{array}$ & Stairs (\#) & Average & SD \\
\hline \multirow{6}{*}{ Ascent } & \multirow{3}{*}{ Walking } & 1 & 1.02 & 0.05 \\
\hline & & 2 & 0.98 & 0.09 \\
\hline & & 3 & 0.99 & 0.10 \\
\hline & \multirow{3}{*}{ Running } & 1 & 1.25 & 0.10 \\
\hline & & 2 & 1.21 & 0.20 \\
\hline & & 3 & 1.28 & 0.09 \\
\hline \multirow{6}{*}{ Descent } & \multirow{3}{*}{ Walking } & 1 & 1.28 & 0.17 \\
\hline & & 2 & 1.25 & 0.11 \\
\hline & & 3 & 1.27 & 0.30 \\
\hline & \multirow{3}{*}{ Running } & 1 & 1.52 & 0.18 \\
\hline & & 2 & 1.50 & 0.14 \\
\hline & & 3 & 1.60 & 0.18 \\
\hline
\end{tabular}

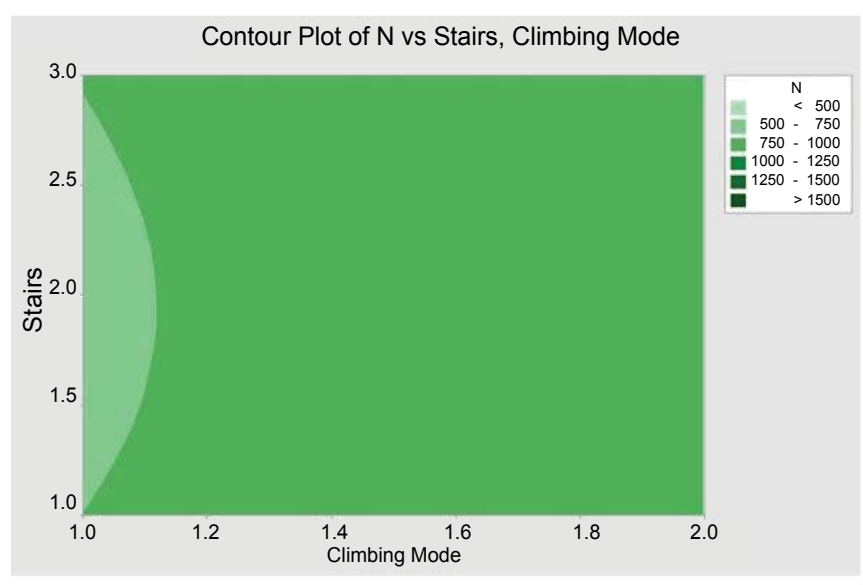

(a) was required more GRF than walking in both stair ascent and decent. During level ground walking, Keller, et al. also reached a similar conclusion that increasing gait speed from walking $(1.5-3.0 \mathrm{~m} / \mathrm{s})$ to running $(3.5-6.0 \mathrm{~m} / \mathrm{s})$ increased high thrust maximum GRF from $1.2 \mathrm{BW}$ to approximately 2.5 BW in both male and female subjects [22]. The SD for the running was relatively larger than walking because the generated vertical GRF was more fluctuating while the subject was performing stair climbing through running (Table 5 and Figure 6).

In order to further analyze the effect of factors on vertical GRF, $3^{1} \times 2^{2} \times 10^{1}$ mixed level factorial design was used because controllable factors have different numbers of levels and experiments involving both qualitative and quantitative factors. In the experiments, stairs has three levels while both climbing mode and climbing style have two levels, and participant has ten levels. In the factorial design, stair 1, 2 and 3 represent stair \#1, \#2 and $\# 3$, respectively. Climbing mode 1 and 2 represent stair ascent and decent respectively. Climbing style 1 and 2 stand for walking and running respectively. P1 to P10 represent the participant 1 to participant 10. Responsible variable is the vertical GRF of all subjects during stair climbing, indicating the peak values of vertical GRF of participants generated under twelve different experimental conditions. Collected data of GRF (in N) were normalized in BW. All 240 vertical GRF data were applied to conduct analysis of variance (ANOVA) and identified the effect of factors.

Table 6 is the ANOVA result of mix-level factorial design with consideration of all interaction effects.

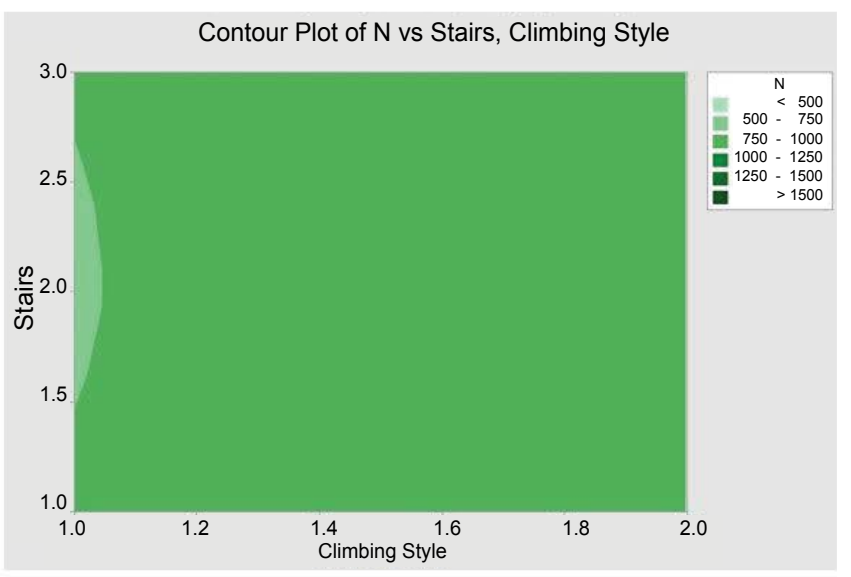

(b)

Figure 7: Contour plots: Effect of stair height and a) Climbing mode; b) Climbing style on vertical GRF (in N). 
Interaction between two factors (six combinations), three factors (four combinations) and four factors (one combination) were also included. The P-value for stairs, climbing mode, climbing style and participant were $0.203,0.000,0.000$, and 0.000 respectively. ANOVA results indicated that the three factors, climbing style, climbing mode and participants have more significant effects than stairs on peak vertical GRF. There is significant difference of vertical GRF between each level of climbing style,

Table 6: Summary of ANOVA results for vertical GRF.

\begin{tabular}{|l|l|l|l|l|l|}
\hline Source & DF & Adj SS & Adj MS & F-value & P-value \\
\hline $\begin{array}{l}\text { Stairs (A) } \\
\text { Climbing } \\
\text { Mode (B) }\end{array}$ & 1 & 4.1067 & 0.05337 & 1.61 & 0.203 \\
\hline $\begin{array}{l}\text { Climbing } \\
\text { Style (C) }\end{array}$ & 1 & 4.0273 & 4.02727 & 121.80 & 0.000 \\
\hline $\begin{array}{l}\text { Participant } \\
\text { (D) }\end{array}$ & 9 & 1.0827 & 0.12030 & 3.64 & 0.000 \\
\hline A*B & 2 & 0.0112 & 0.00559 & 0.17 & 0.845 \\
\hline A*C & 2 & 0.0652 & 0.03258 & 0.99 & 0.376 \\
\hline A*D & 18 & 0.4434 & 0.02463 & 0.75 & 0.758 \\
\hline B*C & 1 & 0.0087 & 0.00869 & 0.26 & 0.609 \\
\hline B*D & 9 & 0.5695 & 0.06327 & 1.91 & 0.056 \\
\hline C*D & 9 & 0.4946 & 0.05495 & 1.66 & 0.106 \\
\hline A*B*C & 2 & 0.0017 & 0.00087 & 0.03 & 0.974 \\
\hline A*B*D & 18 & 0.7281 & 0.04045 & 1.22 & 0.254 \\
\hline A*C*D & 18 & 0.8429 & 0.04683 & 1.42 & 0.136 \\
\hline B*C*D & 9 & 0.8622 & 0.09580 & 2.90 & 0.004 \\
\hline A*B*C*D & 18 & 0.2523 & 0.01402 & 0.42 & 0.980 \\
\hline Error & 120 & 3.9677 & 0.03306 & & \\
\hline Total & 239 & 18.2447 & & & \\
\hline
\end{tabular}

climbing mode and participants. For the interaction effects, only the 3-way interaction effect of climbing mode, climbing style and participant was significant and there is difference between each level on the vertical GRF. Interaction between climbing style and stairs showed that higher stair height during running have relatively higher GRF than two lower stairs. In addition, interaction between climbing mode and stairs indicated that higher stair height during stair descent have highest GRF (Table 6).

Contour plots were used to graphically illustrate the relationship between stair height and other factors in affecting the mean vertical GRF. We assume the climbing mode and style can be quantified for theoretical analysis of their impacts on vertical GRF. As shown in Figure 7a, stair descent generated higher vertical GRF than ascent (about $250 \mathrm{~N}$ more). It also indicated that stair descent is more dangerous and riskier than stair ascent during stair climbing. As shown in Figure 7b, running generated higher vertical GRF than walking (about $250 \mathrm{~N}$ more). It also indicated that running requires more GRF and energy than walking at both stair ascent and descent. Interaction and contour plots explained that individual's climbing style during stair descent may generate different GRF and play an important role in affecting the vertical GRF during stair climbing (Figure 7).

\section{Factors effect on Required Coefficient of Friction (RCOF)}

Vertical GRF and horizontal GRF during foot landing and push-off were collected and used to

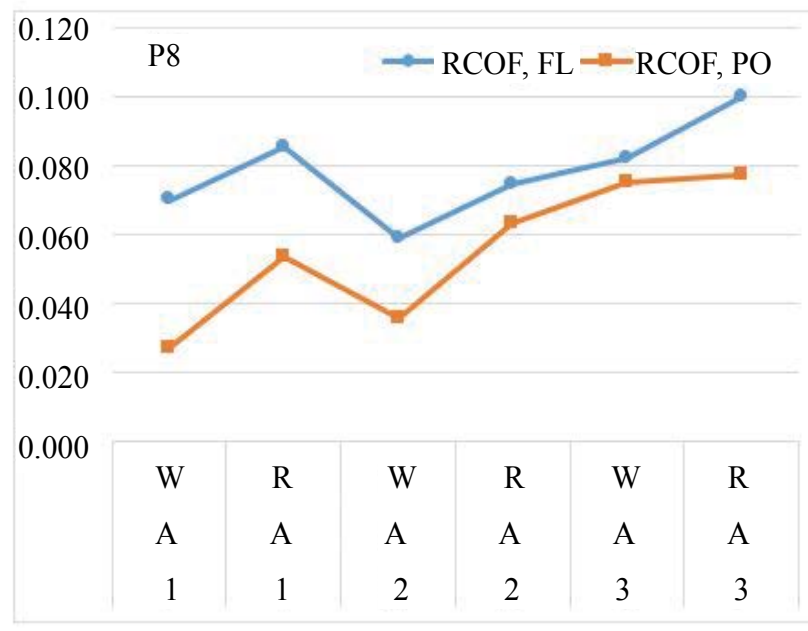

(a)

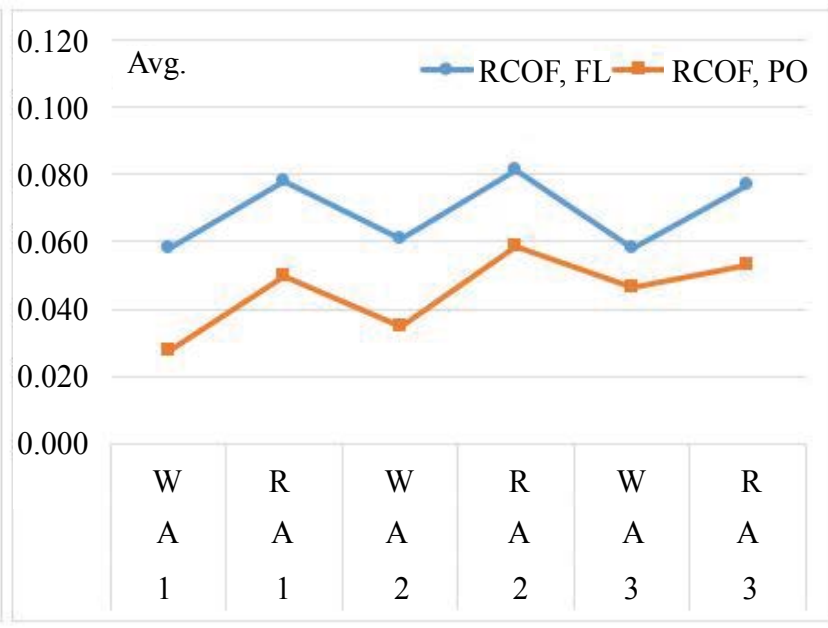

(b)

Figure 8: $\mathrm{RCOF}_{\mathrm{FL}}$ and $\mathrm{RCOF}_{\mathrm{PO}}$ during the stair ascending for: a) P8; b) Average. 
calculate RCOF. Mixed level factorial design method factors on RCOFs during foot landing $\left(\mathrm{RCOF}_{\mathrm{FL}}\right)$ and and ANOVA were applied to investigate effect of push-off $\left(\operatorname{RCOF}_{\mathrm{PO}}\right)$. Table 7 summarized the ANOVA

Table 7: Summary of ANOVA results for RCOFs during Foot Landing $\left(\mathrm{RCOF}_{\mathrm{FL}}\right)$.

\begin{tabular}{|c|c|c|c|c|c|}
\hline Source & DF & Adj SS & Adj MS & F-value & P-value \\
\hline Stair Height (A) & 2 & 0.000102 & 0.000051 & 7.76 & 0.114 \\
\hline Climbing Mode (B) & 1 & 0.000784 & 0.000784 & 119.10 & 0.008 \\
\hline Climbing Style (C) & 1 & 0.002107 & 0.002107 & 320.01 & 0.003 \\
\hline$A * B$ & 2 & 0.000060 & 0.000030 & 4.57 & 0.180 \\
\hline$A^{*} \mathbf{C}$ & 2 & 0.000013 & 0.000006 & 0.95 & 0.513 \\
\hline$B * C$ & 1 & 0.000140 & 0.000140 & 21.28 & 0.044 \\
\hline
\end{tabular}

Table 8: Summary of ANOVA results for RCOFs during Push-Off ( CCOF $\left._{\mathrm{PO}}\right)$.

\begin{tabular}{|l|l|l|l|l|l|}
\hline Source & DF & Adj SS & Adj MS & F-value & P-value \\
\hline Stair Height (A) & 2 & 0.000273 & 0.000136 & 4.49 & 0.182 \\
\hline Climbing Mode (B) & 1 & 0.000645 & 0.000645 & 21.27 & 0.044 \\
\hline Climbing Style (C) & 1 & 0.001587 & 0.001587 & 52.32 & 0.019 \\
\hline A*B & 2 & 0.000067 & 0.000033 & 1.10 & 0.476 \\
\hline A*C & 2 & 0.000042 & 0.000021 & 0.69 & 0.591 \\
\hline B*C & 1 & 0.000085 & 0.000085 & 2.81 & 0.235 \\
\hline Error & 2 & 0.000061 & 0.000030 & & \\
\hline Total & 11 & 0.002760 & & & \\
\hline
\end{tabular}

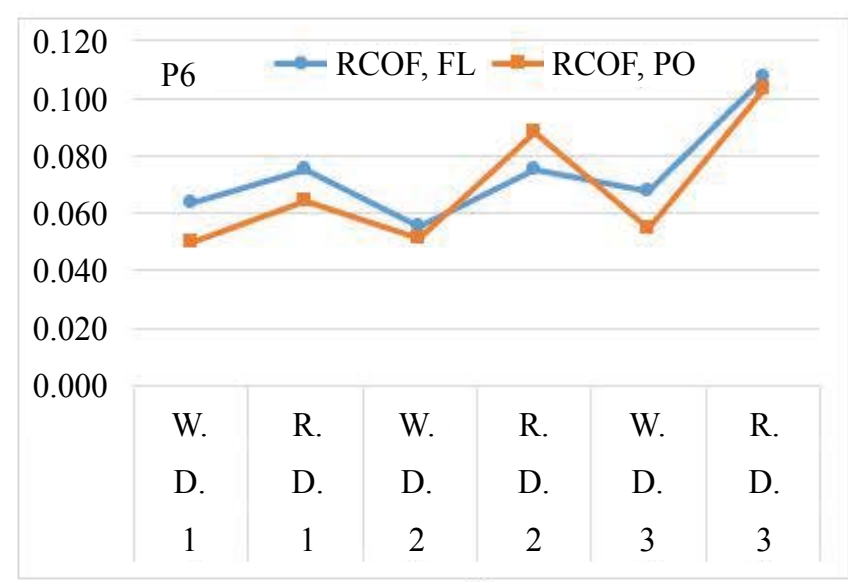

(a)

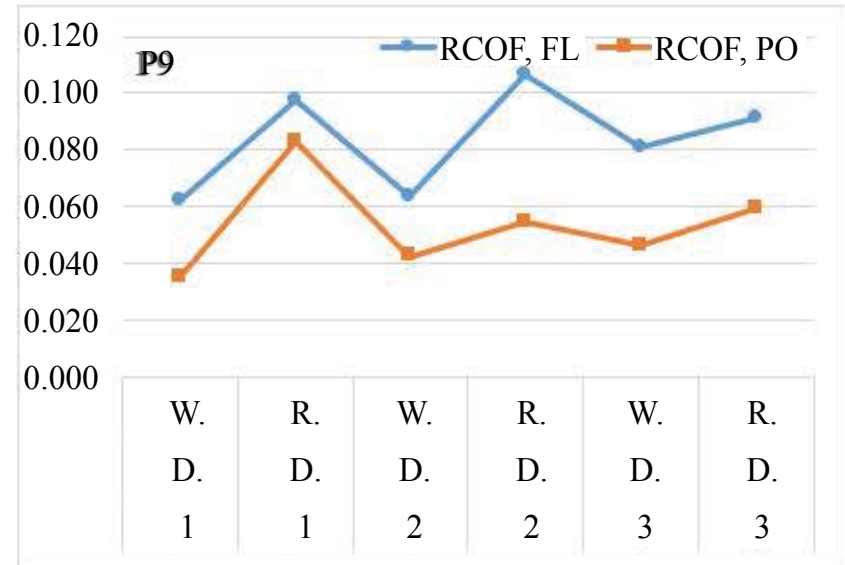

(c)

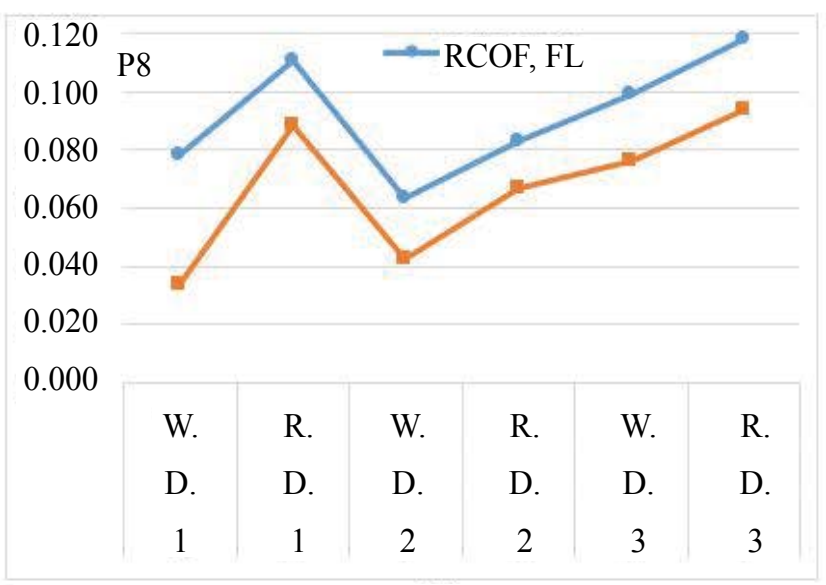

(b)

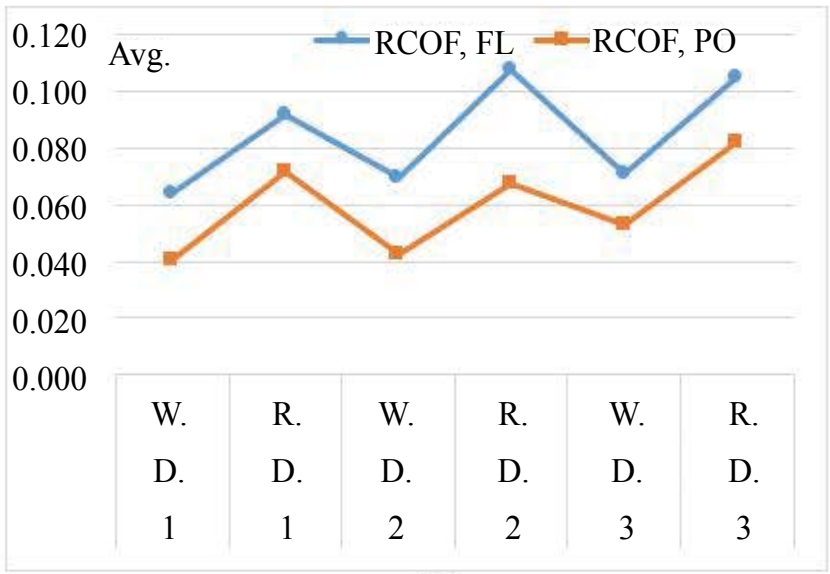

(d)

Figure 9: $\mathrm{RCOF}_{\mathrm{FL}}$ and $\mathrm{RCOF}_{\mathrm{PO}}$ during the stair descending for: a) P6; b) P8; c) P9; d) Average. 
results and indicated that climbing mode and style had significant effects on $\mathrm{RCOF}_{\mathrm{FL}}$, while the effect of stair height on RCOF $_{\mathrm{FL}}$ was not significant at a significant level $\alpha=0.05$ (Table 7).

As shown in Figure 8, RCOF $F$ and $\mathrm{RCOF}_{\mathrm{PO}}$ of individual participant (P8) and average $\mathrm{RCOF}_{\mathrm{FL}}$ and $\mathrm{RCOF}_{\mathrm{PO}}$ of participants were obtained. For stair ascent, the mean $\mathrm{RCOF}_{\mathrm{FL}}$ was in the range of 0.058 to 0.081 while mean RCOF $_{\mathrm{PO}}$ was in range of 0.027 to 0.059 . These results were lower than previous results where approximate $\mathrm{RCOF}_{\mathrm{FL}}$ was in the range between 0.090 to 0.140 and the approximate $\mathrm{RCOF}_{\mathrm{PO}}$ was in the range of 0.060 to 0.080 [1]. The discrepancies between two studies might be attributed to the number of stairs (only four stairs in previous studies, but more stairs used in our study) and locations of force platform. Results also indicated mean RCOF $_{\mathrm{FL}}$ was larger than mean $\mathrm{RCOF}_{\mathrm{PO}}$ during stair ascent. In most cases, both $\mathrm{RCOF}_{\mathrm{FL}}$ and $\mathrm{RCOF}_{\mathrm{PO}}$ of running were higher than walking. Even though the effect of stair height on RCOFs was not as significant as climbing mode and climbing style, but average of RCOF $_{\mathrm{FL}}$ and $\mathrm{RCOF}_{\mathrm{PO}}$ during stair ascent at stair 2 (highest stair height of $0.178 \mathrm{~m}$ ) were slightly higher than those for lower stair heights (Figure 8).

During push-off, ANOVA results as shown in Table 8 indicated that the P-value for stair height, climbing mode, and climbing style were 0.182, 0.044 and 0.019 , respectively. Similar conclusion can be found that climbing mode and style had a significant effect on $\mathrm{RCOF}_{\mathrm{PO}}$ while effect of stair height on $\mathrm{RCOF}_{\mathrm{PO}}$ was not significant at significant level of 0.05 (Table 8).

In addition, $\mathrm{RCOF}_{\mathrm{FL}}$ and $\mathrm{RCOF}_{\mathrm{PO}}$ during stair descending were obtained and plotted in Figure 9. For stair descent, mean $\mathrm{RCOF}_{\mathrm{FL}}$ ranged from 0.064 to 0.108 while mean $\mathrm{RCOF}_{\mathrm{PO}}$ ranged from 0.040 to 0.082 . These results were lower than previous results where the approximate $\mathrm{RCOF}_{\mathrm{FL}}$ was in range of 0.140 to 0.210 and the approximate RCOF $_{\mathrm{PO}}$ was in range of 0.170 to 0.240 during four step stairs [1]. These results were also lower than another previous study where mean $\mathrm{RCOF}_{\mathrm{FL}}$ was in range of 0.50 to 0.70 and the approximate $\mathrm{RCOF}_{\mathrm{PO}}$ was in range of 0.36 to 0.42 for seven steps [7]. The possible reason of different RCOFs can be the different number of steps and the location of platform. There were 7 stairs/steps in Christina and Cavanagh and 8 to 14 steps in this study. The location of platforms were step 2 (transition region) and step 4 (mid-stair region) in Christina and Cavanagh while the platform were placed first step (for descent) and last step (for ascent) in this study. As well as different groups where participants had different anthropometric characteristics and gait patterns between our study and Christina and Cavanagh. Similar phenomena in descending phase that mean $\mathrm{RCOF}_{\mathrm{FL}}$ was larger than mean $\mathrm{RCOF}_{\mathrm{PO}}$ while both $\mathrm{RCOF}_{\mathrm{FL}}$ and $\mathrm{RCOF}_{\mathrm{PO}}$ of running was higher than walking. During stair descending, the effect of stair height on RCOFs was not significant as other factors. But, $\mathrm{RCOF}_{\mathrm{FL}}$ at stair 2 (highest stair height of $0.178 \mathrm{~m}, \mathrm{RCOF}_{\mathrm{FL}}=0.089$ ) was slightly higher than lower stair heights $\left(\mathrm{RCOF}_{\mathrm{FL}}=\right.$ 0.078 for stair $1, \mathrm{RCOF}_{\mathrm{FL}}=0.088$ for stair 3 ) (Figure 9).

In general, results indicated both $\mathrm{RCOF}_{\mathrm{FL}}$ and $\mathrm{RCOF}_{\mathrm{PO}}$ in the case of descending were larger than ascending. This can be explained by gait speed effect on both GRF and RCOF during stair climbing [7]. The walking speeds for double stair condition (two stairs for each step) were believed to be higher than those of single stair condition and affected RCOF values [1]. In addition, the gravity facilitated the downward movement of the body and increased momentum which increased the probability of fall or slip and loss of balance at this moment during stair descending. Thus, running was not recommended during stair descending, as it required higher GRF as well as RCOF, which may cause injuries and fatalities during stair climbing at home and in the workplace.

Compared with previous study [17], this study expended participants size from 5 to 10 as well as horizontal GRF. The collected vertical and horizontal GRF were used to further calculate and analyze the RCOFs during foot strike and pushoff. In addition, the average time of different activities were recorded and used to calculate the momentum and find the relationship between body momentum and vertical GFR during the stair ascent and descent. Similar results that climbing style and climbing mode have a significant effect on GRF, this study also found that participants has a significant effect on GRF. It was also observed that RCOF during foot landing $\left(\mathrm{RCOF}_{\mathrm{FL}}\right)$ was higher than push-off ( RCOF $\left._{\mathrm{PO}}\right)$. Additional GFR and RCOFs results collected from this study may be used to conduct better biomechanical analysis of stair climbing and track the reasons associated with fall at stair climbing. The limitation of this study is to 
exam the coefficient of friction and compare with RCOFs to assess the slip potential and preventing slipping. Outcomes from this research showed the different GRF and RCOF were generated under various conditions (e.g. walking/running, ascent/ descent, stairs). Another limitation of the present study is the fact that relatively small population of 10 with majority of males and only a force plate was used. In the future study, more female participants and several force platforms can be also used to study the effect of gender and position of steps on the GRF and RCOFs as well as COF during complete cycle of stair descending and ascending.

\section{Conclusions}

GRFs and RCOFs are critical to prevent a slip and fall incident during stair climbing. In this study, mixed level factorial design method and ANOVA were applied to investigate the effect of factors, stairs, climbing mode (ascent/descent), climbing style (walking/running) and participants on GRFs and RCOFs. ANOVA results indicated climbing mode, climbing style and participants had more significant effects than stairs did on vertical GRF. It was also found that the effects of climbing mode and climbing style were significant while the effect of stairs on RCOF was not obvious. Stair descent with running showed high gait speed and momentum as well as higher vertical GRF than stair ascent with walking. In addition, results showed that the RCOF value of foot landing $\left(\mathrm{RCOF}_{\mathrm{FL}}\right)$ was higher than push-off $\left(\mathrm{RCOF}_{\mathrm{PO}}\right)$ while both $\mathrm{RCOF}_{\mathrm{FL}}$ and $\mathrm{RCOF}_{\mathrm{PO}}$ of running were higher than walking. The highest GRF and RCOFs occurred during stair descent through running, which potentially increases the risk of injuries and fatalities during stair climbing. In the future study, different stair heights with the same stair length may be added to consider stair height as an independent variable during stair descent through running. In addition, more female participants and multiple force platforms can be involved to study the effect of gender and the position of steps on the GRF and RCOFs. This study suggested the reduced gait speed in stair climbing and lower stair height can reduce vertical GRF as well as RCOF, which may further reduce the possibility of injuries and fatalities during stair climbing at home and workplace.

\section{Acknowledgement}

The authors would like to thank the reviewers for their valuable comments and suggestions.

\section{References}

1. Li KW, Huang SY, Chiu WH (2017) Ground reaction force and required friction during stair ascent and descent. Human Factors and Ergonomics in Manufacturing \& Service Industries 27: 66-73.

2. Silverman $A K$, Neptune RR, Sinitski EH, Wilken JM (2014) Whole-body angular momentum during stair ascent and descent. Gait Posture 39: 1109-1114.

3. Lewis J, Freisinger G, Pan X, Siston R, Schmitt L, et al. (2015) Changes in lower extremity peak angles, moments and muscle activations during stair climbing at different speeds. J Electromyogr Kinesiol 25: 982-989.

4. Jacobs JV (2016) A review of stairway falls and stair negotiation: Lessons learned and future needs to reduce injury. Gait Posture 49: 159-167.

5. Fino P, Lockhart TE (2014) Required coefficient of friction during turning at self-selected slow, normal, and fast walking speeds. J Biomech 47: 1395-1400.

6. Courtney TK, Sorock GS, Manning DP, Collins JW, Holbein-Jenny MA (2001) Occupational slip, trip, and fall-related injuries--can the contribution of slipperiness be isolated? Ergonomics 44: 11181137.

7. Christina KA, Cavanagh PR (2002) Ground reaction forces and frictional demands during stair descent: Effects of age and illumination. Gait Posture 15: 153-158.

8. de Brito Fontana $\mathrm{H}$, Haupenthal A, Ruschel C, Hubert M, Ridehalgh C, et al. (2012) Effect of gender, cadence, and water immersion on ground reaction forces during stationary running. J Orthop Sports Phys Ther 42: 437-443.

9. http://msml.uconn.edu/amti-uconn-collaborationproject/

10. Bertucco M, Cesari P (2009) Dimensional analysis and ground reaction forces for stair climbing: Effects of age and task difficulty. Gait Posture 29: 326-331.

11. Kluitenberg B, Bredeweg SW, Zijlstra S, Zijlstra W, Buist I (2012) Comparison of vertical ground reaction forces during overground and treadmill running. A validation study. BMC Musculoskelet Disord 13: 235.

12. Silva DDO, Thomé DC, Ferreira AS, Aragão FA (2015) Correlation between vertical ground reaction force and knee angular velocity of young and elderly individuals during stair descent. Revista Brasileira de Geriatria e Gerontologia 18: 567-576. 
13. Chen YT, Li KW, Chen YY (2016) Effects of required coefficient of friction for female in different gait. International Conference on Industrial Engineering, Management Science and Application (ICIMSA).

14. Chang WR, Chang CC, Matz S, Lesch MF (2008) A methodology to quantify the stochastic distribution of friction coefficient required for level walking. Applied ergonomics 39: 766-771.

15. Fruin JJ (1971) Pedestrian planning and design. Metropolitan association of urban designers and environmental planners. New York.

16. Choi JH, Galea ER, Hong WH (2014) Individual stair ascent and descent walk speeds measured in a Korean high-rise building. Fire Technology 50: 267-295.

17. Qian X, Kattel BP, Lee S (2017) Analysis of factor effect on ground reaction force during stair climbing. Proceedings of the $6^{\text {th }}$ Annual World Conference of the Society for Industrial and Systems Engineering, Herndon, VA, USA.

18. Qian X, Lee S (2014) The design and analysis of energy efficient building envelopes for the commercial buildings by mixed-level factorial design and statistical methods. Proceeding of American Society of Engineering Education (ASEE), PA, USA.
19. Lee S, Qian X, Garcia S (2013) An analysis of integrated ventilation systems with desiccant wheels for energy conservation and IAQ improvement in commercial buildings. Intl' Journal of Bio-urbanism 3: 105-124.

20. Qian X, Lee S, Soto AM, Chen G (2018) Regression model to predict the higher heating value of poultry waste from proximate analysis. Resources 7: 39.

21. Nilsson J, Thorstensson A (1989) Ground reaction forces at different speeds of human walking and running. Acta Physiol Scand 136: 217-227.

22. Keller TS, Weisberger AM, Ray JL, Hasan SS, Shiavi RG, et al. (1996) Relationship between vertical ground reaction force and speed during walking, slow jogging, and running. Clin Biomech (Bristol, Avon) 11: 253-259.

23. Nimbarte A, Li L (2011) Effect of added weights on the characteristics of vertical ground reaction force during walk-to-run gait transition. Human Movement 12: 81-87.

24. Grabowski AM, Kram R (2008) Effects of velocity and weight support on ground reaction forces and metabolic power during running. J Appl Biomech 24: 288-297. 